\title{
RELATION BETWEEN CELL SIZE AND RESPONSE CHARACTERISTICS OF VESTIBULOSPINAL NEURONS TO LABYRINTH AND NECK INPUTS ${ }^{1}$
}

\author{
R. BOYLE ${ }^{2}$ AND O. POMPEIANO
}

Istituto di Fisiologia Umana, Cattedra I, Università di Pisa, 56100 Pisa, Italy

\begin{abstract}
(1) The activity of 136 Deiters' neurons projecting to lumbosacral segments of the spinal cord has been recorded in decerebrate, partially cerebellectomized cats, and their response characteristics to sinusoidal stimulation of labyrinth and neck receptors have been related to cell size inferred from the conduction velocity of the corresponding axons.

(2) Vestibulospinal neurons with faster conduction velocity and, by inference, having thicker axons and larger cell bodies differed from those neurons having lower axonal conduction velocity by displaying: (i) a relatively irregular interspike interval distribution; (ii) a lower resting discharge rate; (iii) a periodically modulated response to the labyrinth input elicited by sinusoidal tilt around the animal's longitudinal axis $\left(0.026 \mathrm{~Hz}, 10^{\circ}\right)$ characterized by an increase in firing rate during sidedown roll tilt; (iv) an increase in gain (impulses per sec per degree) and phase lag relative to the displacement of the labyrinth response to increasing angular acceleration; $(v)$ a greater gain in labyrinth than neck input, the latter elicited by sinusoidal neck rotation $\left(0.026 \mathrm{~Hz}, 5\right.$ or $\left.10^{\circ}\right)$; and (vi) due to the imbalance of the gains of the separate labyrinth and neck responses and their predictable vectorial summation, a response to both inputs elicited by head rotation resembling that obtained by labyrinth stimulation alone.

(3) These findings are discussed in terms of the reciprocal distribution of synaptic contacts of vestibular and neck afferents on vestibulospinal neurons as a function of cell size. The evidence indicates that, in addition to intrinsic neuronal properties related to cell size, the quantitative and qualitative organization of synaptic inputs represents the critical factor controlling the responsiveness of vestibulospinal neurons.
\end{abstract}

In previous studies, regional differences in response characteristics of neurons in the lateral vestibular nucleus (LVN) of Deiters were found during independent sinusoidal stimulation of macular labyrinth and neck receptors (Boyle and Pompeiano, 1980a, b; cf., Peterson, 1970). The proportion of responsive units and their sensitivity to both inputs were greater in the rostroventral (cLVN) than in the dorsocaudal (ILVN) part of the Deiters' nucleus. These findings could be attributed to differences in the quantitative and qualitative distribution of synaptic contacts of primary macular afferents (cf., Brodal, 1974) and proprioceptive neck afferents to

\footnotetext{
'This work was supported by Public Health Service Research Grant NS 07685-13 from the National Institute of Neurological and Communicative Disorders and Stroke, National Institutes of Health, by a grant from the Consiglio Nazionale delle Ricerche and by a grant in Biologia e Medicina Spaziale from the Consiglio Nazionale delle Ricerche, Italy.

${ }^{2}$ Postdoctoral fellow of the Scuola Normale Superiore, Pisa, Italy and recipient of a grant from the Consiglio Nazionale delle Ricerche.

${ }^{3}$ 'I'o whom correspondence should be addressed at Istituto di Fisiologia Umana, Università di Pisa, Via S. Zeno 31, 56100 Pisa, Italy.
}

the two regions of LVN. However, other parameters may account for the differences in spontaneous and induced discharges of individual LVN neurons to these inputs. For example, it is known that the LVN contains neurons of different sizes, with a predominance, however, of small to medium neurons in the cLVN, the axons of which pass to cervical segments of the spinal cord. On the other hand, small to giant cells which project to the lumbar spinal cord are present in the ILVN (Pompeiano and Brodal, 1957).

Functional properties related to cell size were investigated originally in lumbar spinal motoneurons where a set of experimental evidence has led to the formulation of the "size principle" which states that the smaller the size of the motoneuron, the lower is the threshold and the more effective is the corresponding proprioceptive group Ia pathway in exciting them (Henneman, 1957, 1977; Henneman et al., 1965a, b, 1974; Somjen et al., 1965; cf., Mendell and Henneman, 1971).

There are similarities in the anatomo-functional organization of hindlimb motoneurons and ILVN neurons. First of all, comparable to the proprioceptive group Ia 
afferents terminating on extensor motoneurons (cf., Ponpeiano and Wand, 1980), primary labyrinth afferents terminate mono- and polysynaptically on ILVN neurons (cf., Wilson and Melvill Jones, 1979). Second, similar to the different size motoneurons, the population of vestibulospinal neurons originating from the $1 \mathrm{LVN}$ reflects the wide spectrum of cell body size as reported above; the observation of a direct relationship between the size of the cell body and the axonal diameter of LVN neurons (Deiters, 1865) and physiologic measurements of axonal conduction velocity of LVN neurons activated antidromically from the lumbar cord (Ito et al., 1964; Wilson et al., 1967; Akaike et al., 1973) have confirmed this finding. Finally, these two neuronal populations are linked: vestibulospinal fibers from the ILVN excite mono- and polysynaptically ipsilateral extensor motoneurons (Lund and Pompciano, 1968; Grillner et al., 1970).

For these reasons, we decided to record the unit activity from the selected population of LVN neurons projecting to the lumbosacral segments of the spinal cord and to study the possible correlation between their response characteristics to afferent (labyrinth and neck) inputs and cell size inferred from the conduction velocity of the vestibulospinal axon. If response characteristics are determined by neuronal properties related to cell size, then they should be invariant despite differences in input drive (cf., Henneman et al., 1965a, 1974). On the other hand, if response characteristics depend mainly upon synaptic organization, then differential control of particular neuronal groups could result, provided the relevant input systems distribute to pooled neurons with differing patterns (cf., Burke, 1973, 1979).

In order to avoid anesthetics and cerebellar reverberations of labyrinth and neck afferent volleys (Denoth et al., 1979, 1980; Stanojević et al., 1980; Stanojević, 1981) which might affect both spontaneous or induced discharges of recorded units, all experiments were performed on unanesthetized, decerebrate, and partially cerebellectomized cats. The findings indicate that our sample population of vestibulospinal neurons is not homogeneous in terms of afferent input distribution from labyrinth and neck receptors as previously reported and that qualitative and quantitative differences in synaptic organization determine the responsiveness of these neurons projecting to the hindlimb extensor motoneuronal pool.

A preliminary report of this study has been published previously (Boyle and Pompeiano, 1980c).

\section{Materials and Methods}

Pertinent data were collected from 19 adult cats decerebrated at the precollicular level under ether anesthesia; in addition, the cerebellar vermal cortex and fastigial nuclei were aspirated until the floor of the fourth ventricle was exposed. Unit recording began no earlier than 2 hr after cessation of the anesthesia. The animals were immobilized with pancuronium bromide (Pavulon, N.V. Organon Oss, The Netherlands) and artificially ventilated. The surgical procedures, experimental conditions, methods of recording extracellular unit activity, and marking of the locations of recording sites have already been described in detail, as have the anatomical identi- fication of the vestibular nuclei and the subdivision of the LVN into rostroventral and dorsocaudal parts (Boyle and Pompeiano, 1980a, b). In brief, the animal's head was placed in a stereotaxic frame and fixed in the horizontal position, pitched $10^{\circ}$ nose down. The axis vertebra was held at the level of the exposed spinous process of $\mathrm{C}_{2}$ by a clamp secured on a tilting table; the lower part of the trunk was clamped rigidly to a spinal cord frame at $\mathrm{T}_{11}$ and $\mathrm{L}_{3}$, and pins were inserted through the great trochanter of both femurs to prevent body sway. Both fore- and hindlimbs were extended and clamped.

Rotations of the neck, whole animal (roll tilt), or head alone were accomplished by independent servo-driven hydraulic systems (cf., Denoth et al., 1979, 1980). In particular, rotation of the neck clamp and table simultaneously in both directions of the coronal plane beneath a stationary head produced selective stimulation of neck receptors (neck input). Rotation of the entire stereotaxic equipment and table together about the longitudinal axis produced selective stimulation of labyrinth receptors (labyrinth input). Finally, rotation of the head about the same axis, while the $\mathrm{C}_{2}$ vertebral clamp and table remained stationary in the horizontal position, elicited costimulation of both receptors (neck + labyrinth inputs). Sinusoidal waveforms of $0.026 \mathrm{~Hz}, 5$ or $10^{\circ}$ peak amplitude, were used.

Three stimulating electrodes made of insulated $200-\mu \mathrm{m}$ stainless steel wire and exposed to within $0.5 \mathrm{~mm}$ of their tips, with an interelectrode distance of $1.5 \mathrm{~mm}$, were implanted into the ventral quadrant of the right spinal cord between $L_{1}$ and $L_{2}$. Stimuli for the identification of vestibulospinal neurons consisted of single $0.2-\mathrm{msec}$ rectangular pulses applied in a bipolar manner between two of the three electrode wires. The success of the implantation and the selection of the appropriate pair of electrodes were verified by observing the antidromic field potentials on the cathode ray oscilloscope. Standard criteria for antidromic activation of vestibulospinal neurons were followed, i.e., a constant latency of spike potential from stimulus with no shift in latency at threshold strength, the ability to follow high frequency stimulation, and the abolition of spike potential on collision with a spontaneously occurring action potential (cf., Wilson et al., 1967; Peterson, 1970). The records of antidromically activated neurons were stored on film and verified. Careful attention was given to estimate consistently the distance (in millimeters) from the stimulating and recording sites by exposing the entire spinal cord at the termination of the experiment and repeating the measurement several times. The latency from the foot of the antidromic spike to the stimulus artifact was calculated from magnified ( $\times$ 40) film records. Neurons activated antidromically but not identified histologically as belonging to the LVN have been excluded. In agreement with the known anatomical projections from the LVN (Pompeiano and Brodal, 1957), $107(78.7 \%)$ and $29(21.3 \%)$ antidromically identified vestibulospinal neurons were located histologically in the dorsocaudal and rostroventral regions of the nucleus, respectively. The records of two antidromically identified vestibulospinal neurons located in the LVN are shown in Figure 1.

The unit activity was filtered, amplified, converted to 


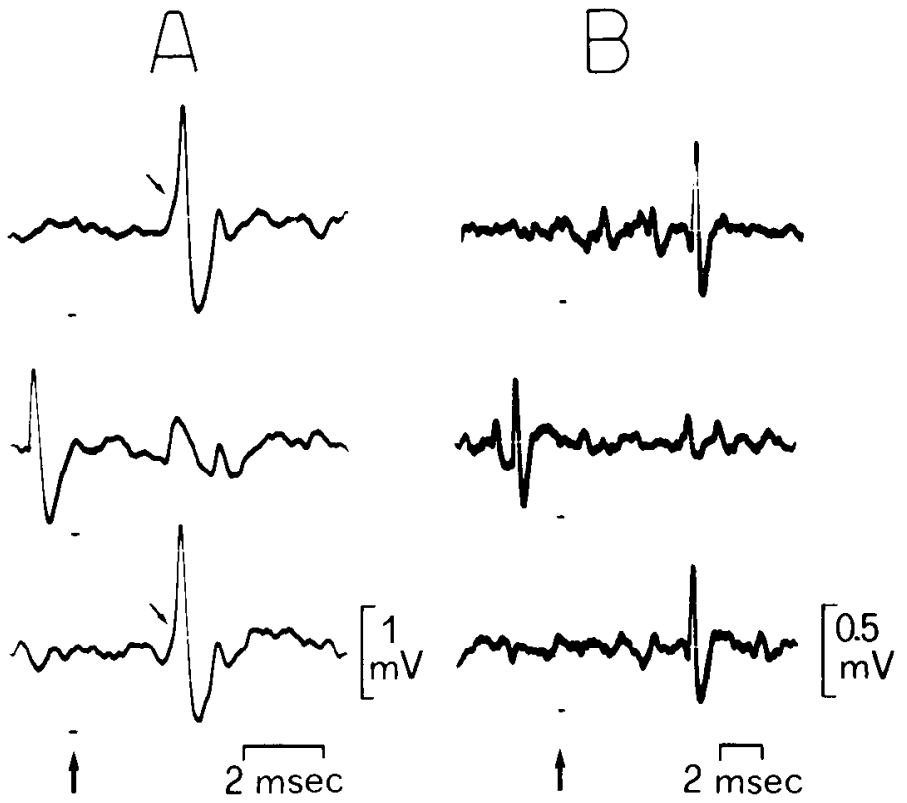

Figure 1. Identification of lateral vestibulospinal neurons. $A$ and $B$, Antidromic action potentials (upper traces), collision of antidromic spikes by spontaneously occurring orthodromic action potentials (middle traces), and reappearance of antidromic spikes (lower traces) in two neurons located histologically in the LVN following single shock stimulation of the $\mathrm{L}_{1}-\mathrm{L}_{2}$ portion of the spinal cord. Stimulus artifact is indicated by the large arrows. The small arrows in $A$ indicate the rising phase of antidromic spike superimposed on top of the antidromic field potential. The conduction velocities of axons were $102.8(A)$ and $45.0(B) \mathrm{m} / \mathrm{sec}$. Both units responded to sinusoidal stimulation of labyrinth and neck receptors (see Fig. 9).

standard pulses, and averaged. The analogue output (sequential pulse density histograms, SPDHs) of the signal averager (Correlatron 1024, Laben) was plotted on an XY plotter (Hewlett-Packard, HP 7035P), and the digital data were stored on punch tape (GNT Automatic A/S, model 3406) and processed off-line with a computer system (HP 2100/A) equipped with a fast Fourier analyzer (HP 5451/B).

The results are based on the quantitative cross-spectral analysis of the averaged unit activity with respect to the first harmonic of response (output) during the rotational stimuli (angular input). The response sensitivity was defined as the percentage of increase (half of peak to peak) of the fundamental component of the mean firing rate per degree of displacement, and the gain was expressed as the absolute change of the firing rate (impulses per sec) per degree. According to the terminology used by Lindsay et al. (1976), the direction of stimulus orientation was designated as side-down when the head or spinous process of $\mathrm{C}_{2}$ was rotated toward the side of the recording electrode and as side-up for rotations toward the opposite side. The phase characteristic of the response is described as the phase difference in arc degrees between the peak of the fundamental component of the unit response and the peak of the side-down displacement of the head (or neck), indicated by $0^{\circ}$. A coherence coefficient varying from 0 to 1.0 was computed on the fundamental component to provide a measure of reliability between the input and output; a value of 1.0 rep- resents a linear, time-invariant, noise-free system. A comparable analysis also was performed on the second and third harmonics. We considered to be positive only those units displaying a stable resting discharge, a coherence coefficient of the first harmonic to successive cycles of stimulation $>0.8$, and a harmonic distortion of the averaged firing rate (calculated from the first 10 harmonics in the Fourier analysis amplitude spectrum) which did not exceed $25 \%$ of the fundamental's amplitude. In addition, units displaying either a saturation or cut-off of the response during periods of stimulation were discarded from analysis.

Raw spike train data from selected segments of unstimulated, background discharges of vestibulospinal neurons were recorded on magnetic tape. The mean interspike interval, standard deviation interval, and coefficient of variation $(\mathrm{CV})$ were calculated off-line. The $\mathrm{CV}$, defined as the standard deviation interval divided by the interval mean, was computed from 500 to 4000 intervals. One hundred or 1000 consecutive intervals were sampled and compared to a second sample taken at random from longer periods of recording using Smirnoff's lambda test. If the two samples were not statistically different at the $5 \%$ level, they were joined to form an enlarged sampling pool.

\section{Results}

Resting discharge activity and conduction velocity of vestibulospinal axons from $L V N$ neurons. All 136 vestibulospinal neurons recorded from the LVN exhibited a background discharge (measured over a period of $30 \mathrm{sec}$ to $2 \mathrm{~min}$ ) in the absence of head (or neck) rotation. Resting discharge rates ranged from 1.7 to $123.2 \mathrm{im}$ pulses/sec and averaged $44.1 \pm 23.8 \mathrm{impulses} / \mathrm{sec} \pm \mathrm{SD}$ (Fig. 2, inset, white columns). A comparable range and mean value $(46.5 \pm 21.9 \mathrm{impulses} / \mathrm{sec} \pm \mathrm{SD})$ of discharge rates also were obtained from a smaller population of 68 units whose regularity of discharge was examined in more detail (Fig. 2, inset, shaded columns). In the latter group of units, a high degree of correlation was observed between the mean interval and the standard deviation interval of the examined spike trains (product moment, $r=0.95$ ). The variability of discharge was measured by the coefficient of variation (CV), defined as the standard deviation of interspike intervals divided by the mean interval, which ranged from 0.078 to 1.09 and averaged $0.263 \pm 0.203$ (mean $\pm \mathrm{SD}, n=68$ ). A continuous relation was found between the interval distribution of the spike train and the mean resting discharge rate: the higher the $\mathrm{CV}$, reflecting a more irregular unit discharge, the lower was the mean background discharge (Fig. 2; paired rank, $p<0.001 ; n=68$ ).

A similar correlation was observed between the unit resting discharge rate and the conduction velocity of the corresponding vestibulospinal axon (Fig. 3). Across the population of all units $(n=136)$, the axon conduction velocity varied in a unimodal fashion from 45.0 to 118.7 $\mathrm{m} / \mathrm{sec}$, with an average value of $84.3 \pm 17.1 \mathrm{~m} / \mathrm{sec} \pm \mathrm{SD}$ (Fig. 3, inset, white columns); comparable values (81.9 $\pm 18.3 \mathrm{~m} / \mathrm{sec} \pm \mathrm{SD}$ ) also were obtained from the population of 68 units described above (Fig. 3, inset, shaded columns). In general, the faster the conduction velocity 


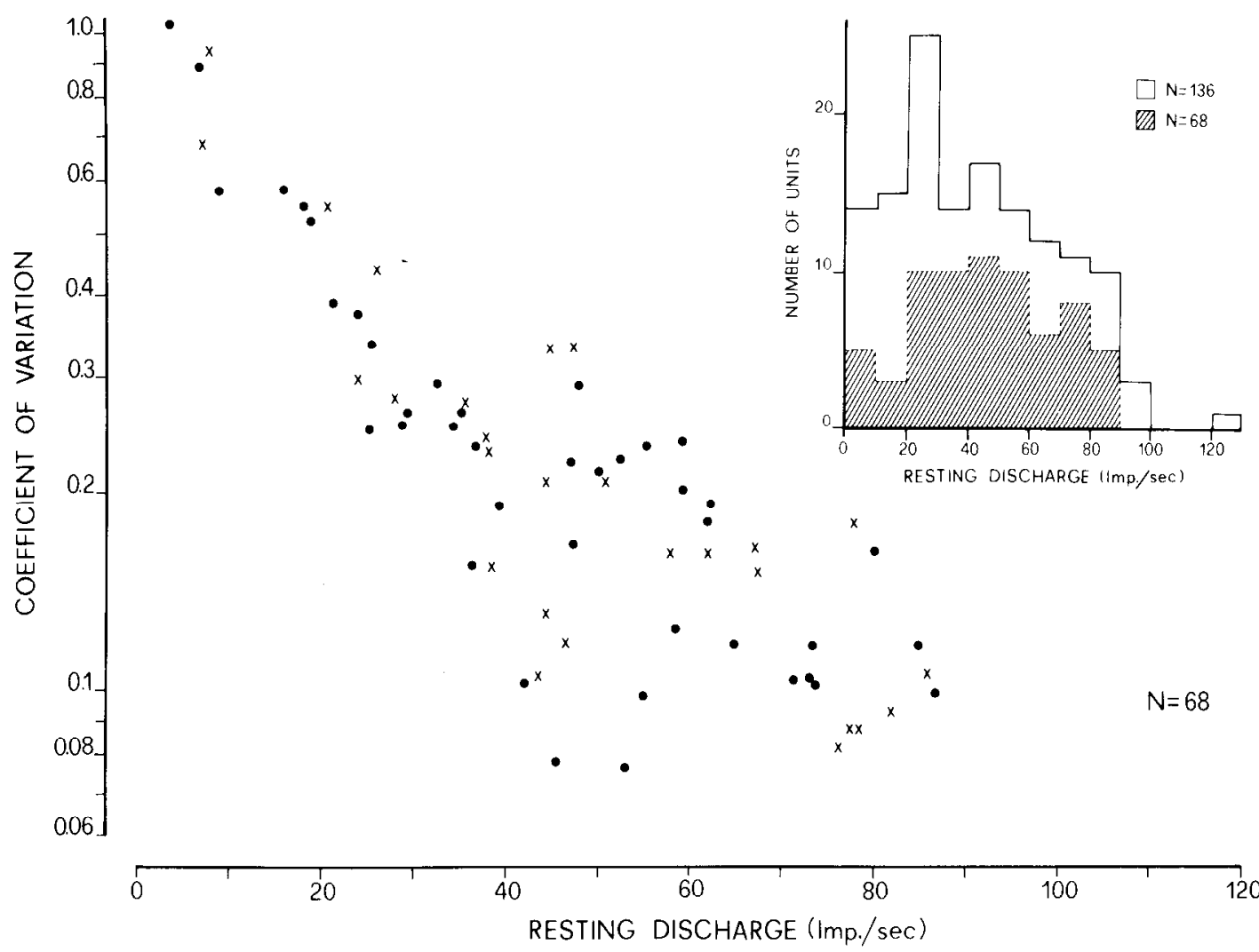

Figure 2. Resting discharge activity of vestibulospinal neurons. The graph shows the relation between the resting discharge rate (measured in impulses per sec) and the coefficient of variation of 68 vestibulospinal neurons. The symbols represent units either responsive $(0, n=41)$ or unresponsive $(\times, n=27)$ to labyrinth stimulation. Inset, Distribution of resting discharge of the general population of antidromically identified LVN units (white columns, $n=136$ ) and the population of units illustrated in the main graph (shaded column.s, $n=68$ ).

of its axon, the lower was the unit discharge rate at rest (paired rank, $p<0.001 ; n=136$ ); the degree of variability of unit discharge showed, therefore, a positive correlation to the axon conduction velocity (same test, $p<0.001$; $n$ $=68$ ).

Gain and sensitivity of unit responses to labyrinth stimulation. Of the 136 vestibulospinal neurons, 80 $(58.8 \%)$ displayed a reliable periodic modulation of their firing rate during sinusoidal tilt at $0.026 \mathrm{~Hz}, 10^{\circ}$ peak amplitude (see Fig. 3, $)$ ). Among the remaining 56 units $(41.2 \%), 48$ did not satisfy the criteria for responsiveness (see Fig. $3, \times$ ). The last 8 units exhibited either an increase in firing rate for both directions of stimulus orientation, thus having a predominant second harmonic of unit response or a periodic modulation but only at higher frequencies of angular tilt (see Fig. 3,0 ); since the results to be described are with respect to the first harmonic of unit response at slow rotations, these units were classified as unresponsive to the stimulus. As shown in Figures 2 and 3, the relationship between the resting discharge activity and the conduction velocity of its axon was sustained for both responsive and unresponsive units.

'The gain of unit responses ranged from 0.05 to 1.99 and averaged $0.48 \pm 0.41 \mathrm{impulse} / \mathrm{sec} /$ degree $\pm \mathrm{SD}(n=80$; see Table I). No acceptable correlation was found across the population of 80 units between the gain and either the background discharge (paired rank, $p>0.05$ ) or the conduction velocity (same test, $p>0.5$ ) when the data from different experiments were pooled. More interesting results, however, were found within individual experiments. For example, in Figure $4 A$, the 7 units recorded in one experiment showed a positive correlation between the gain and the conduction velocity of its axon. These units contrast with those examined in another experiment (Fig. $4 B$ ) in which no relationship was observed. Let us consider the larger sample of responsive units of a third experiment shown in Figure $4 C$. These units are denoted with different symbols to illustrate that either relationship (Fig. 4, $A$ and $B$ ) can be detected from this population of vestibulospinal neurons. These findings may be attributed to sampling from different subpopulations of neurons rather than to large inter-animal variability.

For the population of units reported above, the sensitivity of responses, defined as the percentage of increase in firing rate per degree of tilt, ranged from 0.1 to 7.0 and averaged $1.44 \pm 1.22$ (mean $\pm \mathrm{SD}, n=80$; see Table I). Figure 5 describes the relation between the response sensitivity and other physiologic properties. Units displaying a greater percentage of modulation during roll tilt had in general: (i) a lower background discharge (Fig. $5 A$; paired rank, $p<0.005 ; n=80$ ) and, thus, a larger variability of instantaneous firing rate (same test, $p<$ 


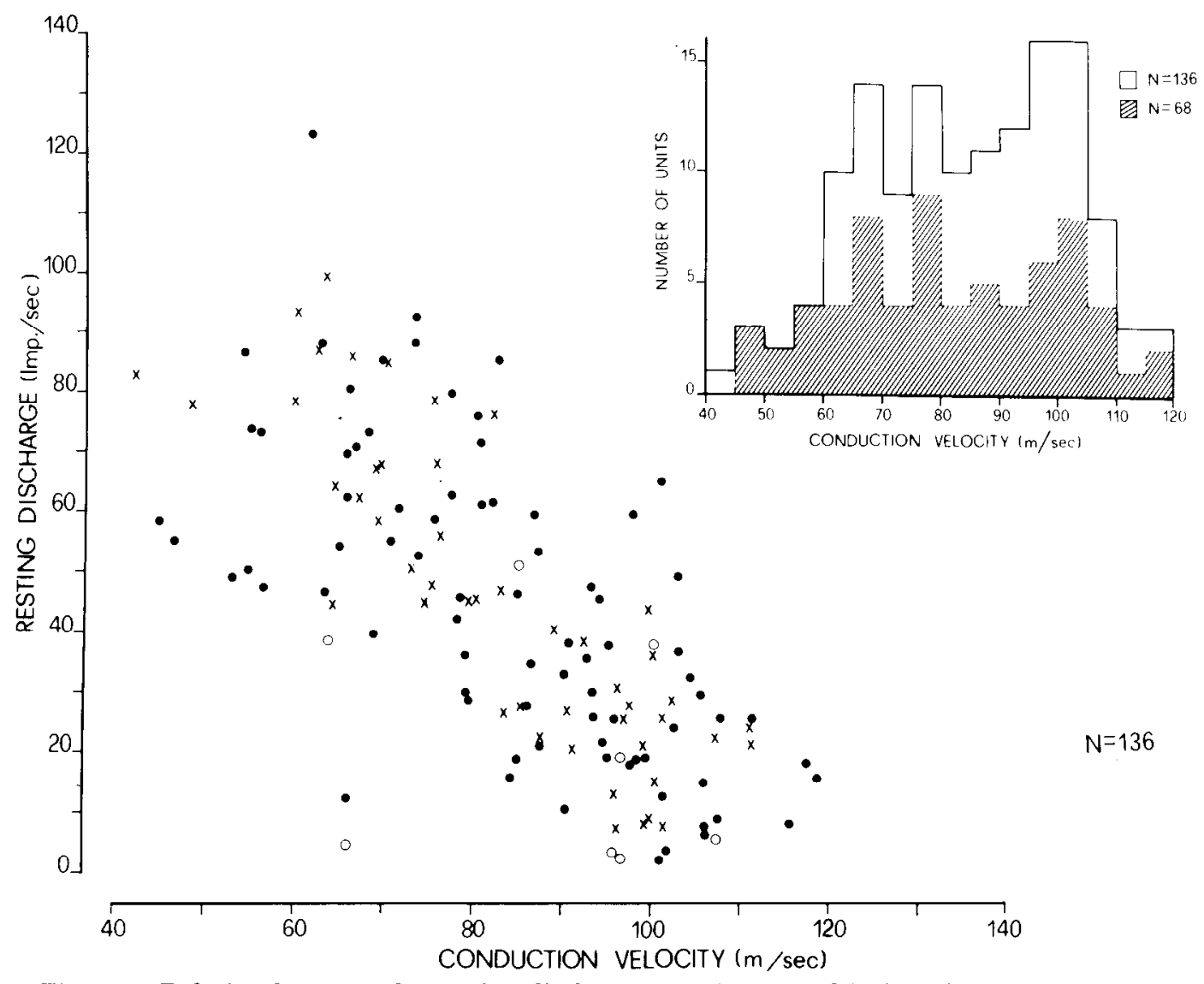

Figure 3. Relation between the resting discharge rate (measured in impulses per sec) of LVN neurons and the conduction velocity of vestibulospinal axons. The graph shows the data of 136 antidromically identified LVN neurons. Symbols represent units either responsive (O; paired rank, $p<0.001 ; n=80$ ) or unresponsive ( $\times$ and $\bigcirc$; same test, $p<0.001 ; n=56$ ) to labyrinth stimulation at standard parameters $\left(0.026 \mathrm{~Hz}, 10^{\circ}\right)$; see the text for an explanation of the unresponsive units indicated by the different symbols. Inset, Distribution of the conduction velocity of the general population of 136 units (white columns) and the population of 68 units illustrated in Figure 2 (shaded columns).

$0.005 ; n=41$ ) and (ii) a faster conduction velocity of their axons (Fig. 5B; same test, $p<0.05 ; n=80$ ). However, caution is needed before concluding that the response sensitivity to labyrinth input is closely related to conduction velocity for the same reasons presented in Figure 4.

Phase relation of unit responses to labyrinth stimulation. Table I categorizes the unit responses to roll tilt $\left(0.026 \mathrm{~Hz}, 10^{\circ}\right)$ into three main patterns of response. The majority of the units $(69$, i.e., $86.25 \%)$ were excited maximally by the direction of animal orientation, displaying either a modulated discharge which reached peak firing rates during side-down tilt ipsilateral to recording site ( $\alpha$ response, phase angle ranging from $\pm 45^{\circ}$ to $0^{\circ} ; n=21$, $26.25 \%)$ or a peak modulation during side-up tilt $(\beta$ response, phase angle ranging from $\pm 135^{\circ}$ to $180^{\circ} ; n=$ $48.60 \%$ ). The remaining 11 unit responses $(13.75 \%)$ in the third category were not in phase with either extreme position of animal displacement.

The relationships between the three parameters examined (resting discharge rate, conduction velocity, and phase relation) are illustrated in Figure 6 (see Table I for details). The units indicated by long vertical lines ( $\alpha$ responses, $n=21$ ) were located primarily on the right side of the diagram and were distinguishable from those displaying the $\beta$ response pattern (short vertical lines, $n$ $=48$ ), by having a lower resting discharge rate (Wilcoxon rank sum test, $p<0.01$ ) and a faster conduction velocity of axons (same test, $p<0.01$ ). No correlation was observed between the gains of responses for these units (same test, $p>0.1$ ); therefore, as described above (Fig. $5)$, the percentage of modulation of the firing rates of $\alpha$ responses was significantly greater than that of $\beta$ responses (same test, $p<0.02$ ). The few responsive units which could not be assigned to either positional category ( $n=11$; medium vertical lines in Fig. 6) had, on the average, values of resting discharge rate, conduction velocity of its axon, gain, and response sensitivity which fell between the two main groups of neurons.

An additional relationship was observed between the phase lead or lag of response and the conduction velocity of each of the 69 positional sensitive neurons: vestibulospinal neurons with slower conduction velocities tended to exhibit larger phase leads with respect to position, whereas those with faster conduction velocities showed larger phase lags (paired rank, $p<0.02 ; n=69$ ). 
'I'ABLE' I

Effects of sinusoidal stimulation of labyrinth and neck receptors (at $0.026 \mathrm{~Hz}$, \pm 5 or $10^{\circ}$ ) on the activity of vestibulospinal neurons located in $I . V N$

Base discharge rate, gain, sensitivity, and conduction velocity of axons are given for responsive units. For each of these parameters, the mean $\pm \mathrm{SD}$ is given (range in parentheses). The phase angle of the first harmonic of the responses refers to side-down displacement of the head (or neck).

\begin{tabular}{|c|c|c|c|c|c|c|c|}
\hline $\begin{array}{l}\text { Phase Angle } \\
\text { of Responses }\end{array}$ & $\begin{array}{l}\text { Number } \\
\text { of Units }\end{array}$ & $\begin{array}{l}\text { Responsive } \\
\text { Units }\end{array}$ & $\begin{array}{c}\text { Unresponsive } \\
\text { Units }\end{array}$ & $\begin{array}{l}\text { Base Discharge } \\
\text { Rate }\end{array}$ & Gain & Sensitivity ${ }^{a}$ & $\begin{array}{c}\text { Conduction Velocity } \\
\text { of Axons }\end{array}$ \\
\hline & & & & impulses/sec & $\begin{array}{c}\text { impulses/sec/ } \\
\text { degree }\end{array}$ & $\%$ & $\mathrm{~m} / \mathrm{sec}$ \\
\hline \multicolumn{8}{|l|}{ Labyrinth input } \\
\hline $\begin{array}{l}\text { From } \pm 45^{\circ} \text { to } \\
0^{\circ}\end{array}$ & & $21(26.25 \%)$ & & $\begin{array}{r}25.0 \pm 18.5 \\
(1.7-88.2)\end{array}$ & $\begin{array}{l}0.41 \pm 0.34 \\
(0.05-1.67)\end{array}$ & $\begin{array}{c}2.18 \pm 1.73 \\
(0.52-7.0)\end{array}$ & $\begin{array}{r}94.4 \pm 12.7 \\
(56.7-111.6)\end{array}$ \\
\hline $\begin{array}{l}\text { From } \pm 135^{\circ} \\
\text { to } 180^{\circ}\end{array}$ & & $48(60.0 \%)$ & & $\begin{array}{l}53.8 \pm 25.5 \\
(8.6-123.2)\end{array}$ & $\begin{array}{l}0.52 \pm 0.47 \\
(0.11-1.99)\end{array}$ & $\begin{array}{c}1.16 \pm 1.02 \\
(0.10-4.0)\end{array}$ & $\begin{array}{c}77.3 \pm 17.3 \\
(45.0-118.7)\end{array}$ \\
\hline $\begin{array}{l}\text { From }+45^{\circ} \text { to } \\
+135^{\circ} \text { lead } \\
\text { and from } \\
-45^{\circ} \text { to } \\
-135^{\circ} \mathrm{lag}\end{array}$ & & $11(13.75 \%)$ & & $\begin{array}{r}41.0 \pm 18.6 \\
(7.6-71.4)\end{array}$ & $\begin{array}{l}0.44 \pm 0.32 \\
(0.07-1.15)\end{array}$ & $\begin{array}{c}1.25 \pm 1.12 \\
(0.38-4.3)\end{array}$ & $\begin{array}{c}87.1 \pm 17.9 \\
(46.7-115.7)\end{array}$ \\
\hline $\begin{array}{l}\text { Total } \\
\text { population }\end{array}$ & 136 & $80(58.8 \%)$ & $56(41.2 \%)$ & $\begin{array}{l}44.5 \pm 22.7 \\
(1.7-123.2)\end{array}$ & $\begin{array}{l}0.48 \pm 0.41 \\
(0.05-1.99)\end{array}$ & $\begin{array}{c}1.44 \pm 1.22 \\
(0.10-7.0)\end{array}$ & $\begin{array}{r}84.3 \pm 17.1 \\
(45.0-118.7)\end{array}$ \\
\hline \multicolumn{8}{|l|}{ Neck input } \\
\hline $\begin{array}{l}\text { From } \pm 45^{\circ} \text { to } \\
0^{\circ}\end{array}$ & & $10(25.6 \%)$ & & $\begin{array}{l}49.8 \pm 29.2 \\
(17.8-112.1)\end{array}$ & $\begin{array}{l}0.34 \pm 0.31 \\
(0.12-1.16)\end{array}$ & $\begin{array}{c}0.70 \pm 0.32 \\
(0.22 \pm 1.01)\end{array}$ & $\begin{array}{l}77.8 \pm 9.4 \\
(62.0-87.4)\end{array}$ \\
\hline $\begin{array}{l}\text { From } \pm 135^{\circ} \\
\text { to } 180^{\circ}\end{array}$ & & $18(46.2 \%)$ & & $\begin{array}{c}36.2 \pm 23.1 \\
(4.4-86.0)\end{array}$ & $\begin{array}{l}0.40 \pm 0.38 \\
(0.02-1.19)\end{array}$ & $\begin{array}{l}1.0 \pm 0.69 \\
(0.33-2.90)\end{array}$ & $\begin{array}{r}90.6 \pm 21.8 \\
(45.0-118.7)\end{array}$ \\
\hline $\begin{array}{l}\text { From }+45^{\circ} \text { to } \\
+135^{\circ} \text { lead } \\
\text { and from } \\
-45^{\circ} \text { to } \\
-135^{\circ} \text { lag }\end{array}$ & & $11(28.2 \%)$ & & $\begin{array}{l}42.3 \pm 27.3 \\
(10.9-99.7)\end{array}$ & $\begin{array}{l}0.47 \pm 0.37 \\
(0.03-1.33)\end{array}$ & $\begin{array}{l}1.13 \pm 0.76 \\
(0.28-2.90)\end{array}$ & $\begin{array}{c}91.3 \pm 14.3 \\
(66.1-111.6)\end{array}$ \\
\hline $\begin{array}{l}\text { Total } \\
\text { population }\end{array}$ & 77 & $39(50.6 \%)$ & $38(49.4 \%)$ & $\begin{array}{r}41.4 \pm 25.8 \\
(4.4-112.1)\end{array}$ & $\begin{array}{l}0.40 \pm 0.36 \\
(0.02-1.33)\end{array}$ & $\begin{array}{c}0.96 \pm 0.62 \\
(0.22-2.90)\end{array}$ & $\begin{array}{c}87.5 \pm 16.5 \\
(45.0-118.7)\end{array}$ \\
\hline
\end{tabular}

"Measured as a percentage of increase of the base discharge rate per degree of displacement.

Response characteristics to changing parameters of angular vestibular stimulation. Figure 7 illustrates the response characteristics of the vestibulospinal neurons tested to changes in the frequency of vestibular stimulation from 0.008 to $0.325 \mathrm{~Hz}\left(10^{\circ}\right)$, resulting in a maximum angular acceleration ranging from 0.02 to $41.8^{\circ} / \mathrm{sec}^{2}$.

Units could be pooled into two main populations. In the first, the slope of the Bode plot gain curve was about $-40 \mathrm{~dB} /$ decade over the tested frequency range $(O$, lower graph) and the averaged phase angle of response maintained a slight phase lead with respect to displacement $(O$, upper graph). In the second group of neurons, the frequency response profile was more consistent with a $-20 \mathrm{~dB} /$ decade gain slope $(\mathbf{O}$, lower graph); concomitant with the gain changes, the phase angle of responses changed from about $+10^{\circ}$ lead to $-78^{\circ}$ lag over the tested frequency range. These frequency responses could be accounted for if we assume that the populations of neurons received afferent volleys from the utricular and from the more dynamic components of macular and/or vertical canal receptors, respectively. Units representing the first population of units had, on the average, a higher resting firing rate $(38.1 \pm 17.8$ impulses/sec; $n=12)$ than those of the second population $(10.4 \pm 6.6$ impulses/sec; $n=6$ ); this difference of means was statistically significant $(t$ test for difference of means, $p<0.01$ ). The difference in the mean conduction velocity of axons between the former $(85.4 \pm 18.7 \mathrm{~m} / \mathrm{sec} ; n=12)$ and latter $(97.5 \pm 7.4 \mathrm{~m} / \mathrm{sec} ; n=6)$ group of units was not significant at an acceptable level.

Unit responses to neck stimulation. Of the $136 \mathrm{LVN}$ neurons described above, 77 were examined quantitatively during slow sinusoidal stimulation of neck receptors $\left(0.026 \mathrm{~Hz}, 5\right.$ or $\left.10^{\circ}\right)$. Thirty-nine units $(50.6 \%)$ displayed a reliable periodic modulation of their firing rate to the sinusoidal stimulus; the remaining 38 units (49.4\%) were unresponsive to neck rotation (Table I). Since these 77 units belong to the general population, the relationship between the resting discharge activity and the conduction velocity also pertains (Figs. 2 and 3 ).

The average gain of response was $0.40 \pm 0.36$ (range, 0.02 to 1.33 ) impulse/sec/degree of neck displacement and the average sensitivity was $0.96 \pm 0.62$ (mean $\pm S D$; range, 0.22 to 2.9 ). No correlation was observed between the gain (and also the response sensitivity) of neck response and either the resting discharge rate or the conduction velocity (paired ranks, $p>0.5 ; n=39$ ).

Similar to the phase angle of responses to the labyrinth 

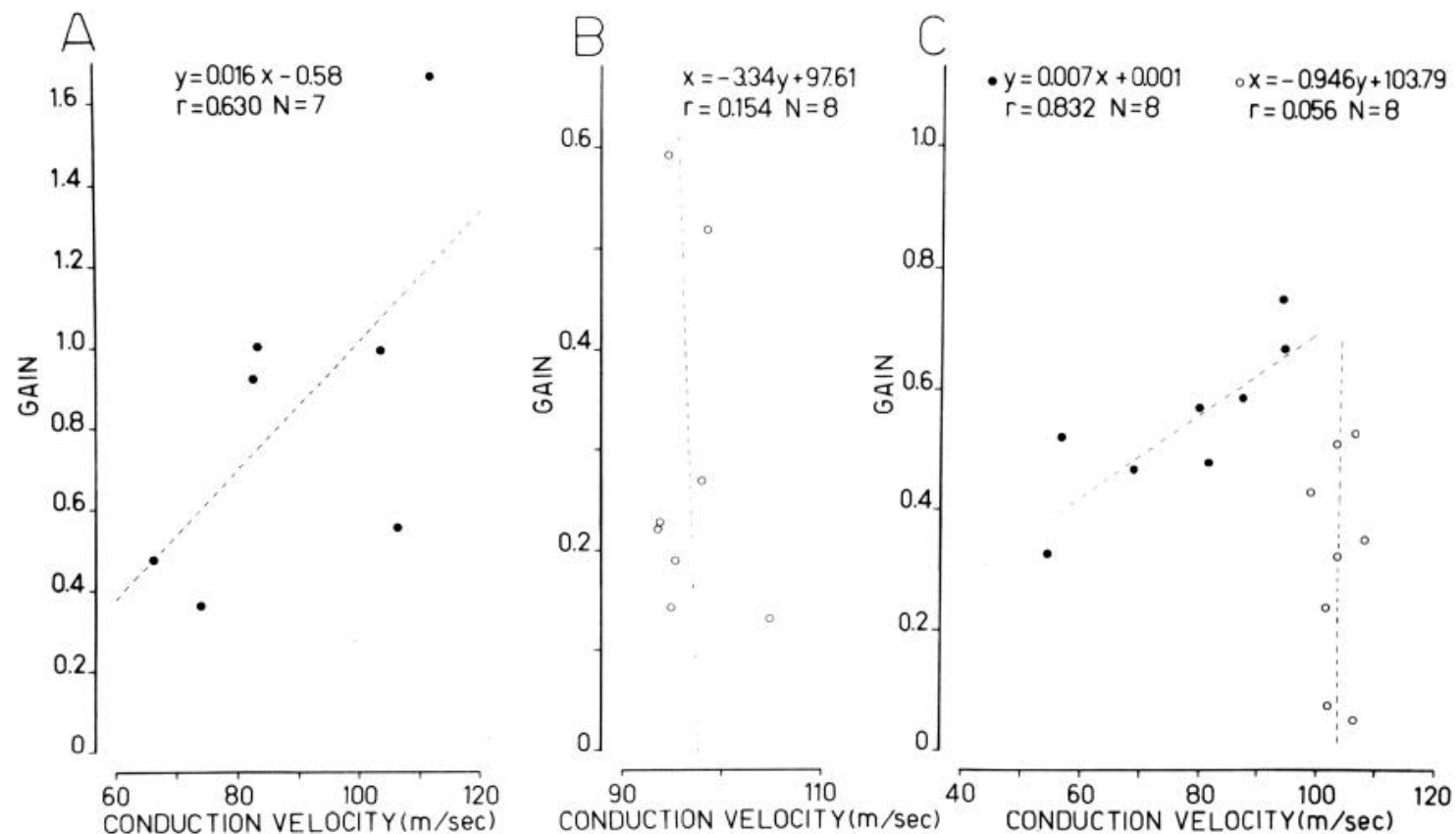

Figure 4. Relation between the conduction velocity of axons and the gain of response of LVN neurons to roll tilt in individual experiments. $A$ and $B, 7(A)$ and $8(B)$ units showing either positive correlation or no relationship, respectively, between the conduction velocity of axons and the gain of response to labyrinth stimulation $\left(0.026 \mathrm{~Hz}, 10^{\circ}\right)$ in two separate experiments. $C, 16$ unit responses recorded in a third separate experiment (two additional unit responses located off-scale have been omitted). For illustrative purposes, two populations of 8 units each, behaving as in $A$ and $B$, have been indicated by solid circles and open circles, respectively. Linear regression and correlation functions are indicated.

input, the majority of $\mathrm{LVN}$ units $(28 / 39$, i.e., $71.8 \%)$ were excited maximally by the direction of neck orientation, preferentially during side-up neck rotation (with the peak of response occurring between $\pm 135^{\circ}$ and $180^{\circ} ; n=18$, $46.2 \%$ ); fewer units were excited during neck rotation in the opposite direction (with the peak of response occurring between $\pm 45^{\circ}$ and $0^{\circ} ; n=10,25.6 \%$ ). The remaining 11 unit responses $(28.2 \%)$ were not in phase with either extreme position of neck displacement. No relationships were found, however, during neck stimulation between units displaying a peak response during side-down or side-up rotation and the other physiologic properties of the units.

Comparison of the unit responses to labyrinth and neck stimulation. No significant differences in the means of the resting discharge rate, the conduction velocity, or the gain were found between unit responses to the labyrinth $(n=80)$ and neck $(n=39)$ inputs (Table I). Interesting differences were observed, however, between the phase relation of unit responses and other physiologic properties of the units. For example, units responding preferentially to side-down neck rotation $(n=10)$ differed from those responding to side-down animal tilt $(n=21)$ by having a higher resting discharge rate (Wilcoxon, $p$ $<0.01$ ) and a slower conduction velocity of axons (same test, $p<0.01$ ); the opposite relations were observed between units responding to side-up neck rotation $(n=$ 18 ) and side-up animal tilt $(n=48)$. Therefore, the resting discharge rate and the conduction velocity of axons of units excited during the side-down orientation of the animal $(n=21)$ were comparable to those excited during side-up neck rotation $(n=18)$.
Convergence and interaction of neck and macular responses. Among the population of LVN units tested to both inputs $(n=77), 36(46.7 \%)$ responded to individual stimulation of both types of receptors, $15(19.5 \%)$ to the labyrinth input, and $3(3.9 \%)$ to the neck input alone; 23 $(29.9 \%)$ were unresponsive to both inputs.

Figure 8 illustrates the relationships between the ratio of gain of neck responses $\left(G_{N}\right)$ and labyrinth responses $\left(G_{L}\right)$ and the physiologic properties of the units $(n=36)$.

Let us consider, for example, the 10 units located on the extreme right side of the figure. These units showed, on the average, a 4-fold greater gain to labyrinth input than to neck input and had relatively faster conduction velocities of axons and lower resting firing rates. The 11 units on the extreme left side of Figure 8 showed the opposite findings, i.e., a 4-fold greater gain to neck input than to labyrinth input, slower conduction velocities, and higher resting firing rates. These relationships are of particular interest because, as described in detail above, no reliable correlations were found between the gains of both the labyrinth and neck responses and the other physiologic properties when studied individually. However, a strong relationship was observed when their ratio of gains was considered: the greater the gain of neck response over labyrinth response, the higher was the resting discharge rate (paired rank, $p<0.001$ ) and the slower was the conduction velocity of unit's axon (same test, $p<0.001$ ) and vice versa. As described in Figure 3, the higher the resting discharge rate of these 36 units, the lower was the conduction velocity of their axons (same test, $p<0.001$ ).

In a previous account (Boyle and Pompeiano, 1981), 

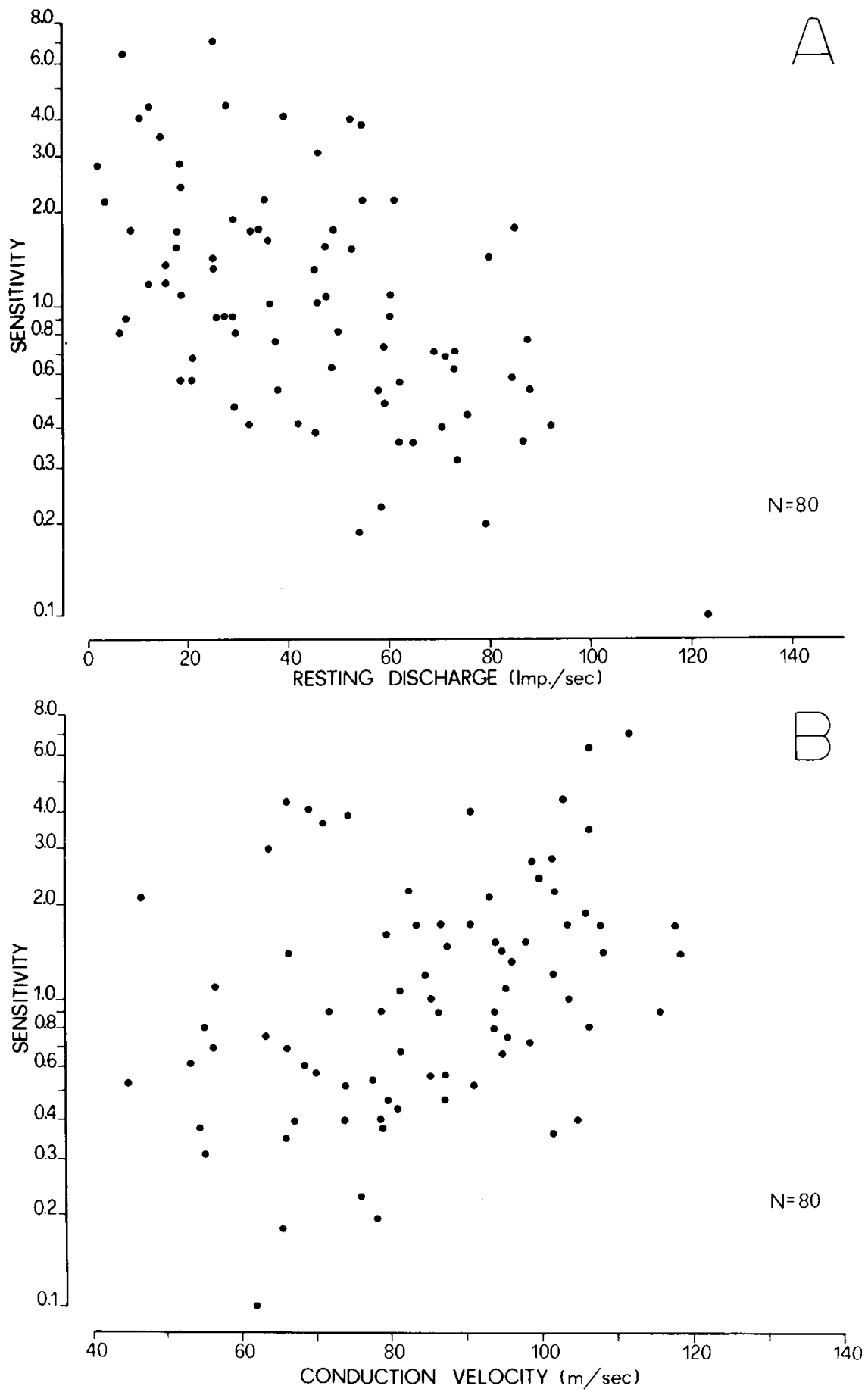

Figure 5. Relations between the resting discharge rate (measured in impulses per sec) or the conduction velocity of axons and the response sensitivity of 80 LVN neurons to sinusoidal stimulation of labyrinth receptors at standard parameters. $A$, Graph showing a negative correlation between the resting discharge rate and response sensitivity. $B$, Weak positive correlation between the conduction velocity of axons and response sensitivity.

the responses of LVN neurons to head rotation, leading to co-stimulation of both neck and labyrinth receptors, were shown to be the result of a linear vectorial summation of the individual responses. For the 11 neurons studied during head rotation here, a high degree of correspondence was observed between the actual gain and phase angle of response and the component values of the predicted vector $\left(\chi^{2}<0.01\right)$. Further, this additive mode of interaction of inputs was maintained over the frequency domain of stimulation from 0.015 to $0.15 \mathrm{~Hz}, 10^{\circ}$ (with a range of maximum angular acceleration from 0.09 to $8.9^{\circ} / \mathrm{sec}^{2}$ ) for the examined units.

Figure 9 illustrates the responses of two lateral vestibulospinal neurons to the three modalities of sensory 


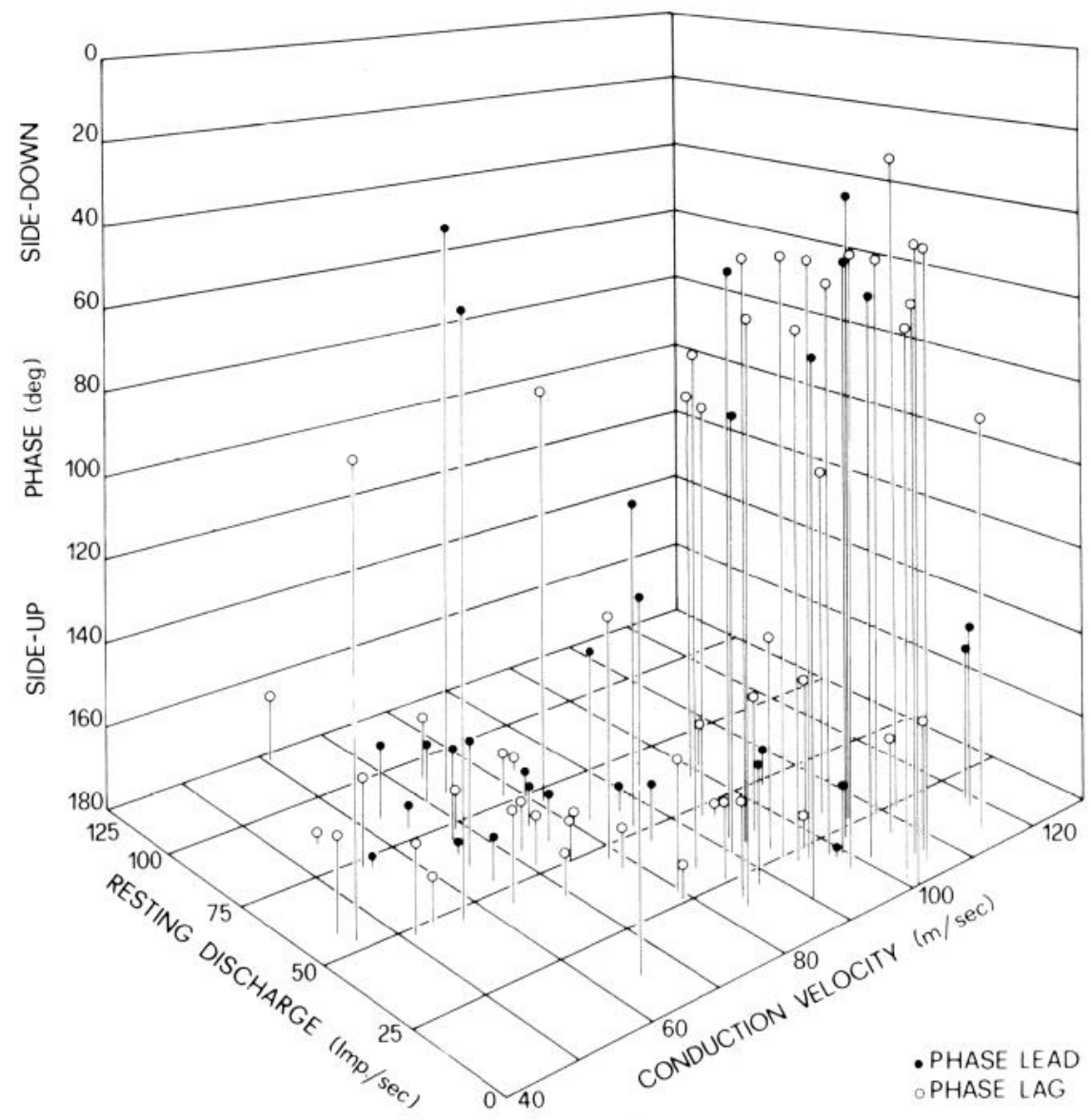

Figure 6. Three-dimensional diagram relating the resting discharge rates (measured in impulses per sec), the conduction velocities of axons, and the phase angles of response of $80 \mathrm{LVN}$ neurons to roll tilt at standard parameters. The relation between resting discharge rate ( $x$ axis), conduction velocity of axons ( $z$ axis), and phase angle of labyrinth response ( $y$ axis) for each unit is shown. Phase angles are relative to peak of side-down displacement of the animal (indicated by $0^{\circ}$ ) and symbols represent either a phase lead $(\Theta)$ or a phase lag $(O)$ from $0^{\circ}$.

stimulation and summarizes the above findings. The unit in Figure $9 A$ showed: $(i)$ a more regular discharge at rest $(\mathrm{CV}=0.126)$, (ii) a higher mean firing rate $(58.4 \mathrm{im}-$ pulses/sec), (iii) a slower conduction velocity of its axon $(45.0 \mathrm{~m} / \mathrm{sec}$; see Fig. $1 B)$, (iv) a peak firing rate during side-up roll tilt ( $\beta$ response), and $(v)$ a greater gain to neck than labyrinth input $\left(G_{N} / G_{L}=2.83\right)$. The separate responses of this unit to the two inputs were approximately in phase with each other $\left(\Delta \phi=13.3^{\circ}\right)$ and, as a consequence of vectorial summation, the unit response to head rotation closely approximated that obtained during neck rotation alone (polar diagram). The unit illustrated in Figure $9 B$ represents the opposite case and had: (i) a relatively irregular unit discharge $(\mathrm{CV}=0.378)$, (ii) a lower mean firing rate (22.7 impulses/sec), (iii) a faster conduction velocity of its axon $(102.8 \mathrm{~m} / \mathrm{sec}$; see Fig. $1 A)$, (iv) a peak firing rate during side-down roll tilt ( $\alpha$ response), and $(v)$ a greater gain to labyrinth than neck input $\left(G_{N} / G_{L}=0.233\right)$. The unit responses were out of phase by $162.2^{\circ}$, but, due to the imbalance of response gains, the resulting unit response during head rotation closely mimicked that observed during labyrinth stimulation alone (polar diagram).

\section{Discussion}

It is known that mammalian vestibular nerve fibers vary in size (Wersäll, 1956; Gacek and Rasmussen, 1961; Walsh et al.; 1972). Physiologic observations indicate that primary vestibular afferents innervating both otolith (Fernández et al., 1972; Goldberg and Fernández, 1975; Fernández and Goldberg, 1976a, b) and semicircular canal receptors (Fernández and Goldberg, 1971; Goldberg and Fernández, 1971a, b, 1975; Blanks et al., 1975; Estes et al., 1975; Keller, 1976; Louie and Kim, 1976; Yagi et al., 1977; Ezure et al., 1978) have different spontaneous discharges and response properties. Relationships also have been observed between the fiber diameter and the physiologic properties of these afferent units. The evidence in the cat indicates that primary afferents with thinner fibers have regular interspike interval distribution (Walsh et al., 1972) and are characterized by a higher resting firing rate and a lower gain to constant acceleration (Blanks et al., 1975). The reverse is true for thicker afferents. The relation between the fiber diameter and the regularity of discharge also was observed in the squirrel monkey (Goldberg and Fernández, 1977). Fur- 


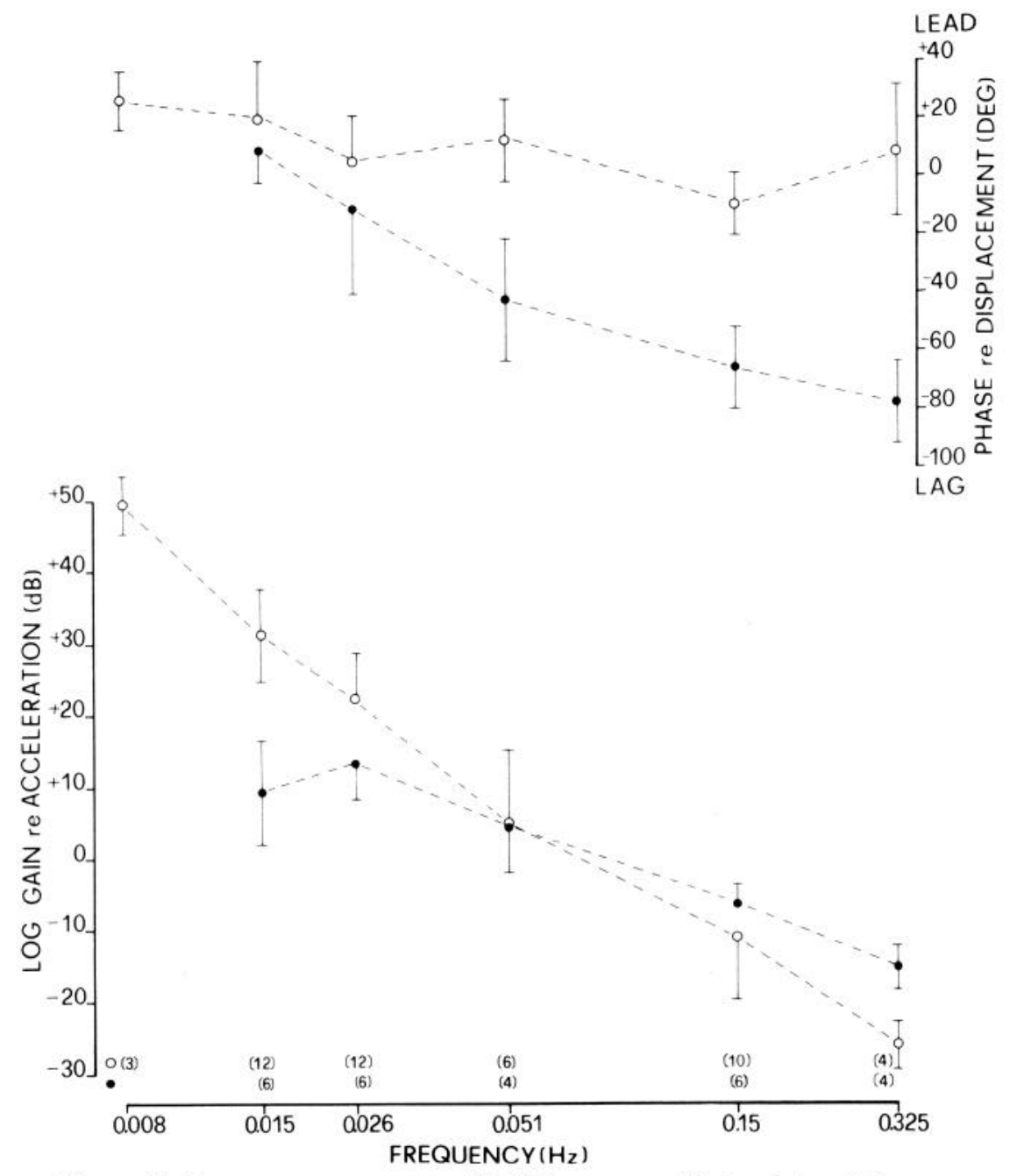

Figure 7. Frequency responses of LVN neurons. Bode plots of the mean $( \pm \mathrm{SD})$ responses of two populations of vestibulospinal units identified by their response characteristics to the increasing frequency of the sinusoidal roll tilt at the peak amplitude of $10^{\circ}$. The gain of the responses is expressed in decibels. The number in each sample is indicated in parentheses. The units of the population of units indicated by solid circles were unresponsive to roll tilt at $0.008 \mathrm{~Hz}$ (not indicated in diagrams). See the text for additional descriptions of each population of units.

ther, afferents innervating the otolith receptors had longer antidromic conduction times, i.e., thinner fibers, than those supplying the ampullar receptors; nevertheless, within each population of otolith and canal units, the shorter the antidromic conduction time, the more irregular was the unit firing pattern.

In the present study, the physiologic properties of different size vestibulospinal neurons projecting to lumbosacral cord have been related to cell size, inferred from the axonal conduction velocity. In fact, a close relation exists between the conduction velocity of axons and cell size as measured by input resistance and conductance (Kernell, 1966; Kernell and Zwaagstra, 1981), critical firing level (Clamann and Henneman, 1976), and direct histological measurements of dye-injected neurons (Barrett and Crill, 1971; Cullheim, 1978; Kernell and Zwaagstra, 1981; cf., however, Brown et al., 1975).

Within our sample population of vestibulospinal neu- rons, significant correlations were found between some of the examined parameters of spontaneous or induced discharges and cell size. These neurons formed a continuum between the more regularly discharging units (based on CV values) characterized also by a slower axonal conduction velocity on the one hand and the more irregularly discharging units with a faster conduction velocity of their axons on the other hand. For sake of simplicity, these neurons will be termed smaller and larger, respectively. Further, the analysis of frequency response profiles to roll tilt indicates that units with higher (and more regular) discharge rates received an input solely from macular vestibular receptors, whereas units with lower and more irregular discharge rates received input(s) from dynamic components of otoliths and/or vertical canals.

In summary, it appears that, in the animal at rest, the functional characteristics of different size vestibular afferents are reflected by comparable physiologic proper- 


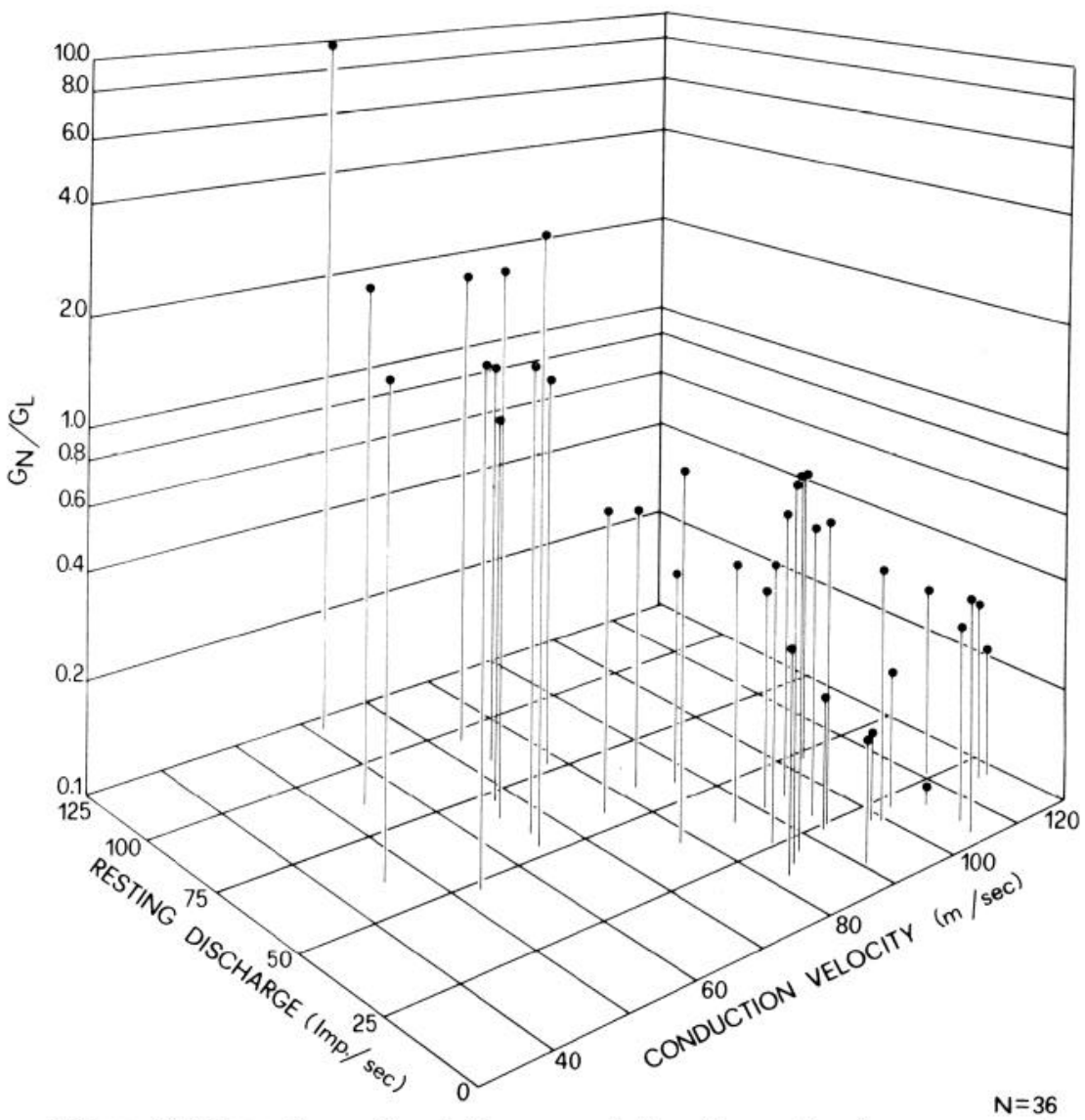

Figure 8. Three-dimensional diagram relating the ratio of response gains $\left(G_{N} / \mathrm{G}_{L}\right)$ to the physiologic properties of LVN neurons. The 36 units received convergent inputs from both labyrinth and neck receptors at standard parameters of testing. The ratio of the gains of neck response $\left(G_{N}\right)$ to the labyrinth response $\left(G_{L}\right)$ ( $y$ axis) is plotted against both the resting discharge rate (measured in impulses per sec; $x$ axis) and the conduction velocity of its axon ( $z$ axis) for each unit. The negative correlations between $G_{N} / G_{L}$ and the conduction velocity and between the resting discharge rate and the conduction velocity and the positive correlation between $G_{N} / G_{L}$ and the resting discharge rate were significant (see text).

ties of different size vestibulospinal neurons projecting to lumbosacral cord. Moreover, properties of afferents innervating the otolith or canal receptors also can be found in vestibulospinal neurons responding to the labyrinth input(s).

Let us now consider the unit responses to roll tilt at standard parameters $\left(0.026 \mathrm{~Hz}, \pm 10^{\circ}\right)$, which can be attributed, for the most part, to stimulation of macular labyrinth receptors (Shimazu and Precht, 1965; Precht, 1974), and determine whether the vestibulospinal neurons projecting to lumbosacral segments of the spinal cord represent a homogeneous population differing only in cell size. In the present experiments, $41.2 \%$ of the vestibulospinal neurons examined were unresponsive to the labyrinth input; however, the two populations of responsive and unresponsive units each covered the entire range of conduction velocity (Fig. 3). This finding indicates that, in addition to differences in the regional distribution of primary vestibular afferents within the LVN (see the introduction), there are also differences in the connectivity of the same afferents which affect dorsocaudal neurons of comparable size. Obviously, this observation does not exclude the fact that the behavior of vestibulospinal neurons $(58.8 \%)$ responsive to labyrinth stimulation is specified by intrinsic neuronal properties (i.e., cell size). The simplest assumption is that this latter sample of responsive neurons represents a homogeneous population in which only cell size varies (cf., Kuno, 1959; Kernell, 1966; Burke, 1967, 1968a, b; Burke and ten Bruggencate, 1971), thus determining the response to afferent vestibular stimulation. Strict application of this hypothesis, however, is not supported by the experimental findings. For example, with respect to the phase angle of response, larger neurons were characterized primarily by an increase in firing rate during sidedown roll tilt, whereas smaller neurons were distinguished by the opposite response pattern. In view of the well known direction of sensory hair orientation in the utriculus, it seems that the response patterns of large and small vestibulospinal neurons reflect the activity of oto- 

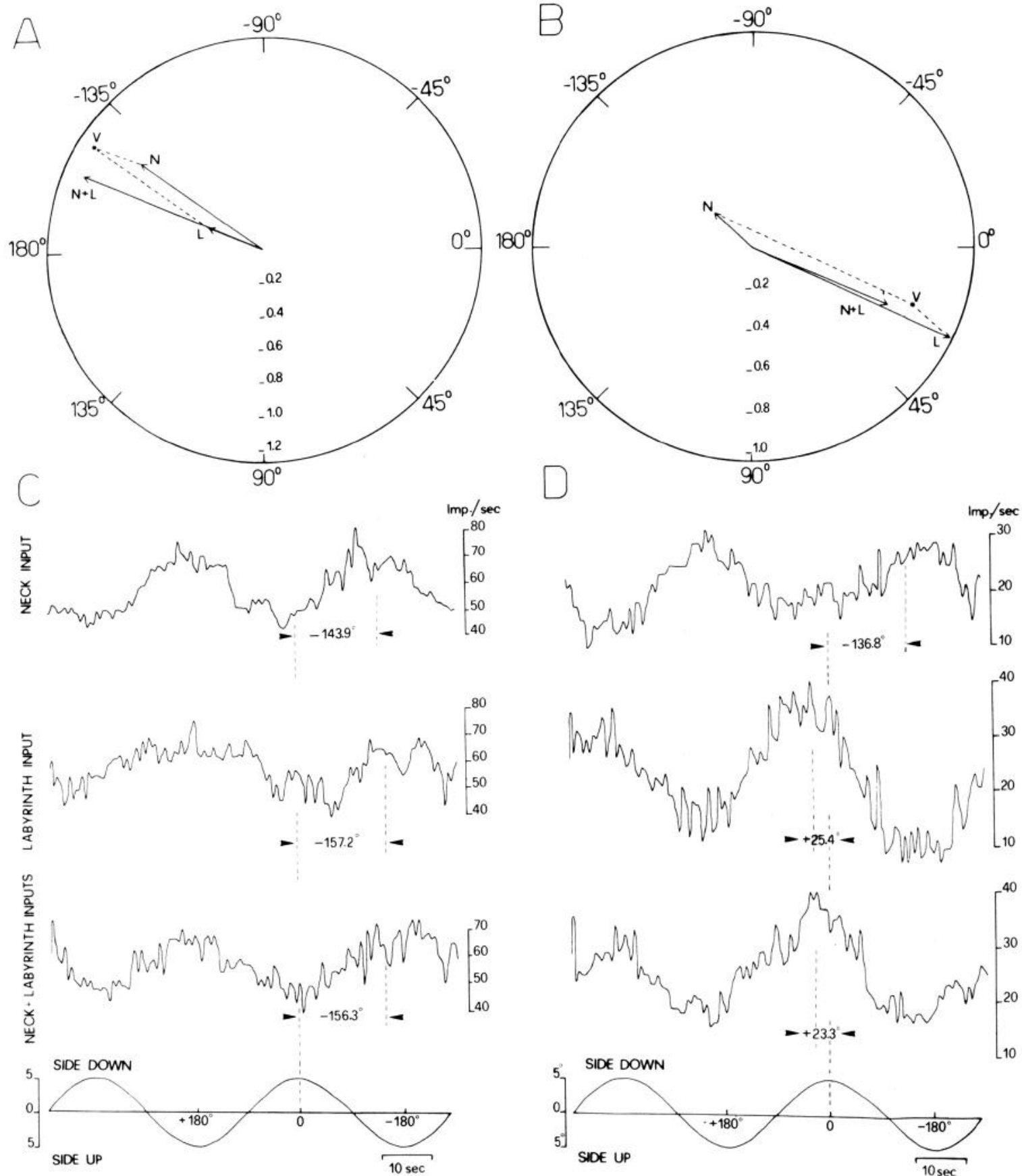

Figure 9. Summary of the data represented by two vestibulospinal neurons located in LVN. Both units were tested at standard parameters of rotation $\left(0.026 \mathrm{~Hz}, 5\right.$ or $\left.10^{\circ}\right)$, and SPDHs for each record were averaged over four sweeps (128 bins, $0.6 \mathrm{sec} / \mathrm{bin}$ width). $A: C$, This unit had an average resting discharge rate of 58.4 impulses/sec, a CV of 0.13 , and a conduction velocity of its axon of $45.0 \mathrm{~m} / \mathrm{sec}$ (see Fig. $1 B$ for its record). The gain, phase angle, and coherence coefficient to neck input (upper trace) were $0.88,-143.9^{\circ}$ lag, and 1.0, respectively, and those values to labyrinth input (second trace) were $0.31,-157.2^{\circ} \mathrm{lag}$, and 0.87 , respectively. The response to head rotation (third trace) had a gain of 1.10 , a phase lag of $-156.3^{\circ}$, and a coherence coefficient of 0.98 . This response to head rotation $(N+L)$ was comparable to the predicted response ( $V$ : gain, 1.18; phase lag, $\left.-147.3^{\circ}\right)$ based on linear vectorial summation of separate neck $(N)$ and labyrinth $(L)$ responses as shown in the polar diagram. $B: D$, This unit showed opposite findings. The average resting discharge rate, $\mathrm{CV}$, and the conduction velocity of its axon were $22.7 \mathrm{impulses} / \mathrm{sec}, 0.38$, and $102.8 \mathrm{~m} / \mathrm{sec}$ (see Fig. $1 A$ for its record), respectively. The gain, phase angle, and coherence coefficient to neck input were $0.24,-136.8^{\circ} \mathrm{lag}$, and 0.92 , respectively, and those values to labyrinth input were $1.03,+25.4^{\circ}$ lead, and 0.93 , respectively. The response to head rotation had a gain of 0.69 , a phase lead of $+23.3^{\circ}$, and a coherence coefficient of 0.95 . As illustrated in the polar diagram, the gain $(0.80)$ and phase angle $\left(+20.2^{\circ}\right)$ of the predicted vectorial response $(V)$ were comparable to those obtained experimentally during head rotation $(N+L)$. 
lith receptors having opposite polarization vectors (cf., Wilson and Melvill Jones, 1979). It appears, therefore, that primary vestibular afferents originating from different populations of otolith receptors are not distributed homogeneously to different size vestibulospinal neurons.

Further, no significant difference was observed in the gain of responses (impulses per sec per degree) between the tested units; thus, larger neurons, by virtue of their lower discharge rate at rest, exhibited a greater percentage of modulation (sensitivity) than smaller neurons. If we assume that primary vestibular afferents having the same polarization vector produce an equal density of synaptic endings on different size neurons, then the gain of response would be higher in small neurons due to a higher input resistance than in large neurons. The fact that smaller neurons generally had the same gain to macular stimulation as larger neurons is at variance with this hypothesis. It may be said that smaller neurons having a higher background discharge were close to response saturation due to an excess of input excitation from vestibular afferents. This, however, was not the case because the firing rate of these neurons actually could be enhanced by an extralabyrinthine input, which was less effective on larger neurons (see below).

An alternative hypothesis to the equal density principle, according to which every responsive neuron regardless of its size receives an equal density of excitatory endings of macular afferents, is that the critical factor controlling the responsiveness of the vestibulospinal pool is the progressive difference in quantitative and qualitative organization of the synaptic input as a function of size. This could be due to either an overall increase in the density of synaptic contacts on large neurons or a relative increase of synaptic contacts on the cell body and/or proximal dendrites of these neurons, which may increase the effectiveness of the labyrinth input. Whatever the mechanisms responsible for response gain, they do not intervene equally in determining the magnitude of response of comparable size vestibulospinal neurons. This can be seen by the differences in gain to the labyrinth input of neurons of comparable size recorded from the same experiment (Fig. 4). This finding may be attributed to size-independent differences either in the intrinsic properties of the neurons themselves or in the connectivity of the macular labyrinthine pathway. ${ }^{4}$

A final consideration should be devoted to the responses of different size vestibulospinal neurons to neck afferent stimulation. No correlation was found between gain, sensitivity, or phase characteristics of the neck response and conduction velocity. Nevertheless, interesting differences were found when the population of units responding to the neck input were compared to those receiving the labyrinth input. For example, larger neu-

\footnotetext{
${ }^{4}$ The hypothesis that size alone does not determine all of the properties of the neurons is supported by the results of recent experiments showing that small motoneurons of comparable size could have different firing rates in response to a given repetitive stimulus of the homonymous nerve, as well as different gain constants of the linear component of stimulus-response curve relating the output of the motoneurons to Ia input frequency (Harris and Henneman, 1977; Wand et al., 1980).
}

rons were characterized by a response during side-down animal tilt and during side-up neck rotation; different response patterns were generally observed in smaller neurons. Further, if we consider the units receiving a convergent input from both receptors, a close relation was found when the ratio of gain of neck response $\left(G_{N}\right)$ and labyrinth response $\left(G_{L}\right)$ was compared to cell size. The smaller the size of the vestibulospinal neuron, the more prominent was the relative gain of neck response with respect to labyrinth response (i.e., high $G_{N} / G_{L}$ ); the opposite was true for larger neurons. This finding indicates a size-dependent arrangement affecting either the density or efficacy of the synaptic organization of labyrinth and neck afferent signals on this population of vestibulospinal neurons controlling the hindlimb muscles. These reciprocal differences in gain of vestibulospinal neurons as a function of cell size, coupled with the significant differences in phase characteristics and the predictable vectorial addition of responses to the two afferent inputs, will allow a precise definition of the output of vestibulospinal neurons during simultaneous stimulation of both receptors elicited by head rotation (Fig. 9).

Further experiments are required to investigate the coupling of the different size vestibulospinal neurons and extensor motoneurons during the labyrinth and neck reflexes.

\section{References}

Akaike, T., V. V. Fanardjian, M. Ito, M. Kumada, and H. Nakajima (1973) Electrophysiological analysis of the vestibulospinal reflex pathway of rabbit. I. Classification of tract cells. Exp. Brain Res. 17: 477-496.

Barrett, J. N., and W. E. Crill (1971) Specific membrane resistance resistivity of dye-injected cat motoneurons. Brain Res. 28: $556-561$.

Blanks, R. H. J., M. S. Estes, and C. H. Markham (1975) Physiologic characteristics of vestibular first-order canal neurons in the cat. II. Response to constant angular acceleration. J. Neurophysiol. 38: 1250-1268.

Boyle, R., and O. Pompeiano (1980a) Reciprocal responses to sinusoidal tilt of neurons in Deiters' nucleus and their dynamic characteristics. Arch. Ital. Biol. 118: 1-32.

Boyle, R., and O. Pompeiano (1980b) Responses of vestibulospinal neurons to sinusoidal rotation of neck. J. Neurophysiol. 44: 633-649.

Boyle, R., and O. Pompeiano (1980c) Response characteristics of vestibulospinal neurons of different sizes to sinusoidal stimulation of macular labyrinth receptors. Soc. Neurosci. Abstr. 6: 225.

Boyle, R., and O. Pompeiano (1981) Convergence and interaction of neck and macular vestibular inputs on vestibulospinal neurons. J. Neurophysiol. 45: 852-868.

Brodal, A. (1974) Anatony of the vestibular nuclei and their connections. In Handbook of Sensory Physiology. Vol. VI/1: Vestibular System. Part 1: Basic Mechanisms, H. H. Kornhuber, ed., pp. 239-352, Springer-Verlag, Berlin.

Brown, A. G., C. R. House, P. K. Rose, and P. J. Snow (1975) The cell of origin of the spinocervical tract. J. Physiol. (Lond.) 249: 65-66P.

Burke, R. E. (1967) Motor unit types of cat triceps surae muscle. J. Physiol. (Lond.) 193: 141-160.

Burke, R. E. (1968a) Group Ia synaptic input to fast and slow twitch motor units of cat triceps surae. J. Physiol. (Lond.) 196: 605-630. 
Burke, R. E. (1968b) Firing patterns of gastrocnemius motor units in the decerebrate cat. J. Physiol. (Lond.) 196: 631-654.

Burke, R. E. (1973) On the central nervous system control of fast and slow twitch motor units. In New Developments in Electromyography and Clinical Neurophysiology, J. E. Desmedt, ed., Vol. 3, pp. 69-94, Karger, Basel, Switzerland.

Burke, R. E. (1979) The role of synaptic organization in the control of motor unit activity during movement. In Progress in Brain Research. Vol. 50: Reflex Control of Posture and Movement, R. Granit and O. Pompeiano, eds., pp. 61-67, Elsevier/North-Holland Biomedical Press, Amsterdam.

Burke, R. E., and G. ten Bruggencate (1971) Electrotonic characteristics of alpha motoneurones of varying size. J. Physiol. (Lond.) 212: 1-20.

Clamann, H. P., and E. Henneman (1976) Electrical measurement of axon diameter and its use in relating size to critical firing level. J. Neurophysiol. 39: 844-851.

Cullheim, S. (1978) Relations between cell body size, axon diameter and axon conduction velocity of cat sciatic $\alpha$-motoneurons stained with horseradish peroxidase. Neurosci. Lett. 8: 17-20.

Deiters, O. (1865) Untersuchung über Gehirn und Rückenmark des Menschen und der Säugethiere, Braunschweig (quoted by S. Culheim, 1978).

Denoth, F., P. C. Magherini, O. Pompeiano, and M. Stanojević (1979) Responses of Purkinje cells of the cerebellar vermis to neck and macular vestibular inputs. Pfluegers Arch. 381: 8798.

Denoth, F., P. C. Magherini, O. Pompeiano, and M. Stanojević (1980) Responses of Purkinje cells of cerebellar vermis to sinusoidal rotation of neck. J. Neurophysiol. 43: 46-59.

Estes, M. S., R. H. I. Blanks, and C. H. Markham (1975) Physiologic characteristics of vestibular first-order canal neurons in the cat. I. Response plane determination and resting discharge characteristics. J. Neurophysiol. 38: 1232-1249.

Ezure, K., R. H. Schor, and Yoshida K. (1978) The response of horizontal semicircular canal afferents to sinusoidal rotation in the cat. Exp. Brain Res. 33: 27-39.

Fernández, C., and .J. M. Goldberg (1971) Physiology of peripheral neurons innervating semicircular canals of the squirrel monkey. II. Response to sinusoidal stimulation and dynamics of peripheral vestibular system. J. Neurophysiol. 34: 661-675.

Fernández, C., and J. M. Goldberg (1976a) Physiology of peripheral neurons innervating otolith organs of the squirrel monkey. I. Response to static tilts and to long-duration centrifugal force. J. Neurophysiol. 39: 970-984.

Fernández, C., and J. M. Goldberg (1976b) Physiology of peripheral neurons innervating otolith organs of the squirrel monkey. III. Response dynamics. J. Neurophysiol. 39: 9961008 .

Fernández, C., J. M. Goldberg, and W. K. Abend (1972) Response to static tilts of peripheral neurons innervating otolith organs of the squirrel monkey. J. Neurophysiol. 35: 978-997.

Gacek, R. R., and G. L. Rasmussen (1961) Fiber analysis of the statoacoustic nerve of the guinea pig, cat and monkey. Anat. Rec. 139: 455-463.

Goldberg, J. M., and C. Fernández (1971a) Physiology of peripheral neurons innervating semicircular canals of the squirrel monkey. I. Resting discharge and response to constant angular accelerations. J. Neurophysiol. 34: 635-660.

Goldberg, J. M., and C. Fernández (1971b) Physiology of peripheral neurons innervating semicircular canals of the squirrel monkey. III. Variations among units in their discharge properties. J. Neurophysiol. 34: 676-684.

Goldberg, J. M., and C. Fernández (1975) Responses of peripheral vestibular neurons to angular and linear accelerations in the squirrel monkey. Acta Otolaryngol. (Stockh.) 80: 101110 .
Goldberg, J. M., and C. Fernández (1977) Conduction times and background discharge of vestibular afferents. Brain Res. 122: 545-550.

Grillner, S., T. Hongo, and S. Lund (1970) The vestibulospinal tract. Effects on alpha motoneurones in the lumbosacral cord in the cat. Exp. Brain Res. 10: 94-120.

Harris, D. A., and E. Henneman (1977) Identification of two species of alpha motoneurons in cat's plantaris pool. J. Neurophysiol. 40: 16-25.

Henneman, E. (1957) Relations between size and neurons and their susceptibility to discharge. Science 126: 1345-1346.

Henneman, E. (1977) Functional organization of motoneuron pools: The size principle. Proceedings of the Twenty-seventh International Congress of Physiological Sciences, Paris, Vol. 12, p. 50.

Henneman, E., G. Somjen, and D. O. Carpenter (1965a) Functional significance of cell size in spinal motoneurons. J. Neurophysiol. 28: 560-580.

Henneman, E., G. Somjen, and D. O. Carpenter (1965b) Excitability and inhibitability of motoneurons of different sizes. J. Neurophysiol. 28: 599-620.

Henneman, E., H. P. Clamann, J. D. Gillies, and R. D. Skinner (1974) Rank order of motoneurons within a pool: Law of combination. J. Neurophysiol. 37: 1338-1349.

Ito, M., T. Hongo, M. Yoshida, Y. Okada, and K. Obata (1964) Antidromic and transsynaptic activation of Deiters' neurones induced from the spinal cord. Jpn. J. Physiol. 14: 638-658.

Keller, E. L. (1976) Behavior of horizontal semicircular canal afferents in alert monkey during vestibular and optokinetic stimulation. Exp. Brain Res. 24: 459-471.

Kernell, D. (1966) Input resistance, electrical excitability and size of ventral horn cells in cat spinal cord. Science 152: 16371640.

Kernell, D., and B. Zwaagstra (1981) Input conductance, axonal conduction velocity and cell size among hindlimb motoneurones of the cat. Brain Res. 204: 311-326.

Kuno, M. (1959) Excitability following antidromic activation in spinal motoneurones supplying red muscles. J. Physiol. (Lond.) 149: 374-393.

Lindsay, K. W., T. D. M. Roberts, and J. R. Rosenberg (1976) Asymmetric tonic labyrinth reflexes and their interaction with neck reflexes in the decerebrate cat. J. Physiol. (Lond.) 261: 583-601.

Louie, A. W., and J. Kim (1976) The response of 8th nerve fibers to horizontal sinusoidal oscillations in the alert monkey. Exp. Brain Res. 24: 447-457.

Lund, S., and O. Pompeiano (1968) Monosynaptic excitation of alpha-motoneurones from supraspinal structures in the cat. Acta Physiol. Scand. 73: 1-21.

Mendell, L. M., and E. Henneman (1971) Terminals of single Ia fibers: Location, density, and distribution within a pool of 300 homonymous motoneurons. J. Neurophysiol. 34: 171-187.

Peterson, B. W. (1970) Distribution of neural responses to tilting within vestibular nuclei of the cat. J. Neurophysiol. 33: $750-767$.

Pompeiano, O., and A. Brodal (1957) The origin of vestibulospinal fibres in the cat. An experimental-anatomical study, with comments on the descending medial longitudinal fasciculus. Arch. Ital. Biol. 95: 166-195.

Pompeiano, O., and P. Wand (1980) Critical firing level of gastrocnemius-soleus motoneurons showing a prolonged discharge following vibration of the homonymous muscles. Pfluegers Arch. 385: 263-268.

Precht, W. (1974) The physiology of the vestibular nuclei. In Handbook of Sensory Physiology. Vol. VI/1: Vestibular System. Part 1: Basic Mechanisms, H. H. Kornhuber, ed., pp. 353-416, Springer-Verlag, Berlin.

Shimazu, H., and W. Precht (1965) Tonic and kinetic responses 
of cat's vestibular neurons to horizontal angular acceleration. J. Neurophysiol. 28: 991-1013.

Somjen, G., D. O. Carpenter, and E. Henneman (1965) Responses of motoneurons of different sizes to graded stimulation of supraspinal centers of the brain. J. Neurophysiol. 28: 958-965.

Stanojević, M. (1981) Responses of cerebellar fastigial neurons to neck and macular vestibular inputs. Pfluegers Arch., in press.

Stanojević, M., L. Erway, B. Ghelarducci, O. Pompeiano, and W. D. Willis, Jr. (1980) A comparison of the response characteristics of cerebellar fastigial and vermal cortex neurons to sinusoidal stimulation of macular vestibular receptors. Pfluegers Arch. 385: 95-104.

Walsh, B. T., J. B. Miller, R. R. Gacek, and N. Y. S. Kiang (1972) Spontaneous activity in the eighth cranial nerve of the cat. Int. J. Neurosci. 3: 221-236.
Wand, P., O. Pompeiano, and N. A. Fayein (1980) Impulse decoding process in extensor motoneurons of different size during the vibration reflex. Arch. Ital. Biol. 118: 205-242.

Wersäll, J. (1956) Studies on the structure and innervation of the sensory epithelium of the cristae ampullaris in the guinea pig. A light and electron microscopic investigation. Acta Otolaryngol. (Suppl.) (Stockh.) 126: 1-85.

Wilson, J., M. Kato, B. W. Peterson, and R. M. Wylie.(1967) A single-unit analysis of the organization of Deiters' nucleus. J. Neurophysiol. 30: 603-619.

Wilson, V. J., and G. Melvill Jones (1979) Mammalian Vestibular Physiology, Plenum Press, New York.

Yagi, T., N. E. Simpson, and C. H. Markham (1977) The relationship of conduction velocity to other physiological properties of the cat's horizontal canal neurons. Exp. Brain Res. 30: 587-600. 